J. Lake Sci. (湖泊科学), 2015, 27(1):24-30

http: //www. jlakes.org. E-mail : jlakes@niglas.ac.cn

(C) 2015 by Journal of Lake Sciences

\title{
面向流量管理的水动力对淡水藻类影响的概念机制
}

\author{
陈瑞弘 ${ }^{1}$, 李飞鹏 ${ }^{1 * *}$, 张海平 ${ }^{1}$, 陈 玲 $^{1}$, 赵建夫 ${ }^{1}$, 黄子寒 ${ }^{2}$ \\ (1: 同济大学环境科学与工程学院,上海 200092) \\ ( 2 : 复旦大学环境科学与工程系,上海 200433)
}

\begin{abstract}
摘 要: 许多证据表明缓慢的水动力条件是水华暴发的重要诱因,尽管以临界流速和水体置换为基础的流量管理实践在 水华控制中已见成效,但受限于水动力对藻类生长小生境的干扰机制尚不明晰, 长期的流量管理实践效果并不理想. 在 长期野外观测、围隔实验和室内模拟等一系列研究的基础上, 以现有水动力对藻类影响机制的讨论为依据, 从细胞学角 度提出了水动力对藻类生长影响的 3 种不同的概念机制, 即低强度的水力扰动导致藻细胞外扩散层厚度变薄, 有利于周 边水体向藻细胞输送营养物质, 促进藻类生长; 中等强度的水力扰动导致藻类营养盐吸收及光合作用能力受损, 抑制藻 类生长; 高强度的水流剪切导致藻细胞壁破损. 基于该机制认为流量管理中临界流速应分别从水体置换和细胞学两方面 考虑. 研究结果可为流量管理中控制藻类水华暴发和维持水体水质的策略提供重要的理论支持.
\end{abstract}

关键词: 水动力;水华藻类;临界流速;流量管理;概念机制

\section{Conceptual mechanism of hydrodynamic impacts on freshwater algae for flow manage- ment}

CHEN Ruihong ${ }^{1}$, LI Feipeng ${ }^{1}$, ZHANG Haiping ${ }^{1}$, CHEN Ling ${ }^{1}$, ZHAO Jianfu ${ }^{1} \&$ HUANG Zihan ${ }^{2}$

(1: College of Environmental Science and Engineering, Tongji University, Shanghai 200092, P. R. China)

(2: Department of Environmental Science and Engineering, Fudan University, Shanghai 200433, P. R. China)

Abstract: Numerous studies have shown that low flow condition is the main trigger of algae bloom and flow management is widely acknowledged as a strategy for inhibiting bloom development based on critical flow velocity and replacement. Due to the underlying intervention mechanism is still not clear, long-term practices of flow management are not very effective. Based on the research progress and a series of studies through long-term observation, enclosure and laboratory experiments, we present the conceptual mechanism that there existed three different mechanisms of hydrodynamic impacts on freshwater algae: (1) low turbulent flow results in the thickness of cell diffuse layer thinner in favor of nutrients transport from water phase to algae cell, which is preferred by algae growth; (2) medium turbulent flow is harmful to nutrients absorption and light availability of algae and inhibits the algae growth; (3) high shear force can damage the algae cell walls, which are individually determinant in different levels of flow intensity. According to theories, critical flow velocity should be applied from two different aspects of water replacement and cytology in flow management. The results will be of great scientific significance in order to control algle bloom and remain the water quality in flow management.

Keywords: Hydrodynamics; blooming algae; critical flow velocity ; flow management; conceptual mechanism

目前,我国水体富营养化形势严峻, 藻类水华发生的频率和强度不断增加. 国内外已经就水华暴发成因 和基本条件展开了大量研究 ${ }^{[1-2]}$, 普遍认为藻类发生异常繁殖及引起水华的主要环境因素可归结为 3 个方 面: (1) 氮、磷等营养盐充足; (2) 适宜的气候条件 (温度、光照等); (3) 缓慢的水流流态. 上述 3 方面因素中,环 境气候条件难以控制. 到目前为止, 国内外主要还是采取营养盐控制措施. 然而削减营养盐负荷不仅代价昂

* 国家自然科学基金项目 (51379146,51409190)资助. 2014-03-19 收稿;2014-06-05 收修改稿. 陈瑞弘 (1989 ), 男,硕士研究生;E-mail : chen_ruihong@foxmail. com.

** 通信作者;E-mail:lifeipeng@ tongji. edu.cn. 
贵, 而且由于严重的内源和面源污染, 不一定能获得理想的效果 ${ }^{[3]}$. 随着全球气候变化趋势的加剧, 干旱状 况频现,一些水体流速减缓, 水力停留时间增加, 一定程度上为有害藻类生长和增殖提供了适宜的条 件 ${ }^{[1,4-5]}$. 随着大量水电项目的开发, 诸多河流演变成水库, 水动力条件减弱, 水动力条件发生变化后水体的 富营养化态势及对水华暴发的影响日益成为社会和学术界关注的焦点.

水动力对藻类的影响直观表现为水力冲刷效应, 许多研究表明水力冲刷增强或流量增大能够减缓藻类 的比增长率, 并认为存在一个临界流速, 当流速大于临界流速时即可抑制藻类水华暴发,如澳大利亚采取基 于临界流速的流量管理措施, 虽然显著降低了水华暴发的风险, 但受限于水动力对藻类小生境影响机制的 不明晰, 长期的水华控制和水质维持效果并不理想 ${ }^{[6-7]}$. 通过对当前研究的综述, 梁培瑜等 ${ }^{[8]}$ 认为不同水动 力因子 (包括流速、流量和水体扰动等) 对藻类的影响不尽相同, 但水动力对藻类影响的定量关系尚不明确, 弄清这种滞后规律能进一步精确预测水华暴发. 而且,在当前水资源状况相对紧缺的情况下,使用过大的流 量来防治水华暴发并不现实, 因此探索水动力对藻类水华的影响机制对流量管理等策略的实施具有十分重 要的意义. 本研究在分析水动力与藻类关系的基础上, 根据当前流量管理中存在的问题, 结合我们长期的野 外观测模拟、围隔实验和室内模拟等一系列研究, 提出了水动力对藻类生长影响的概念机制及在流量管理 中控制水华和维持水质的策略,以期为有害藻类水华的控制提供科学依据.

\section{1 水动力与藻类生长关系的描述}

基于长期观测和统计分析, 多数研究发现水动力与藻类生长呈现显著的负相关关系. 例如, Isvánovics 等 ${ }^{[9]}$ 对东欧 3 条河流 5 8 年的分析发现, 每小时的流量和叶绿素 a (Chl. a) 总体上呈负相关关系. Desortová 等 ${ }^{[10]}$ 对捷克 Vltava 河 2002-2007 年的密集观测发现, Chl. a 与流速呈显著负相关 $\left(R^{2}=0.359\right.$, $P<0.001)$. 王玲玲等 ${ }^{[11]}$ 发现香溪河库湾流速与 Chl. a 浓度存在负相关关系, 且相关性可采用对数曲线进行 描述. 小型封闭水体中也发现了这种关系. 中心湖是位于崇明岛前卫村的典型的小型封闭水体,有 5 条相互 连通的河道, 李飞鹏等 ${ }^{[12-13]}$ 通过对中心湖将近 5 年(2007 年 4 月至 2011 年 11 月) 的观测分析, 发现了 Chl.a 与流速的显著负相关关系 $\left(R^{2}=0.618, P<0.001\right)$, 尤其是对于北河段和南河段,两个河道营养盐水平相 当,受阳光照射条件相当,但受地形和盛行风向的影响, 北河段平均流速为 $0.14 \mathrm{~m} / \mathrm{s}$, Chl. a 长年处于最低水 平, 南河段平均流速仅为 $0.09 \mathrm{~m} / \mathrm{s}, \mathrm{Chl}$. a 则长年处于较高水平, 两个河道之间 Chl. a 的差异与不同的水动 力条件关系密切 ${ }^{[14]}$.

水动力条件较弱也被证明是导致水体水华频发的主要原因. Paerl 等 ${ }^{[15]}$ 通过对东非 Victoria 湖、北美 Erie 湖、中国太湖和欧洲波罗的海的蓝藻水华分析, 认为弱的水体紊动非常有利于蓝藻上浮至水面形成水华. 王丽平等 ${ }^{[16]}$ 对三峡水库支流大宁河的调查发现,3 月和 5 月水华暴发期间 Chl. a 浓度与流速均呈显著负相 关关系, 认为流速和流量都对藻细胞增殖或聚集产生直接或间接的影响. 王红萍等 ${ }^{[17]}$ 对汉江水华的水文因 素分析发现, 流量增大减缓了藻类的比增长速率, 有利于抑制水华的发生. 龙天渝等 ${ }^{[18-19]}$ 对嘉陵江、香溪河 等研究表明, 三峡水库建成后支流流速变缓是导致水华频繁的主要原因. 这些观测结论均表明增强水动力 条件能够对藻类生长产生一定的抑制作用,一定程度上为通过流量管理和水力调度等方式控制富营养化和 藻类水华提供基本依据.

\section{2 基于临界流速的流量管理及存在的问题}

在对藻类和水动力的野外观测和统计的基础上, 多数研究者认为存在一个临界流速, 当流速大于或者 小于这个临界条件时, 浮游植物的生长速率就会减缓. 国内外关于临界流速的界定多通过模拟实验或模型 研究得到. 王华等 ${ }^{[20]}$ 对铜绿微囊藻的室内扰动实验表明, 水动力条件对藻类生长影响明显, 低流速有利于藻 类生长, 而在静止与 $0.2 \mathrm{~m} / \mathrm{s}$ 的高流速条件下藻类的生长受到抑制. 廖平安等 ${ }^{[21]}$ 以故宫简子河为例, 分析了 推流对水体水华的抑制效果, 证明了增加水体流速可以在一定程度上抑制藻类生长, 延缓水华发生, 提出应 该通过实验研究藻类水华暴发的临界流速. 此后, 许多研究者通过不同的方式研究了影响浮游植物生长的 临界流速 (表 1). 以防治水体水华暴发为目标的水体置换和生态水力调度技术多以临界水动力条件 (流量、 流速、水位等) 为依据 ${ }^{[22-23]}$. 
表 1 影响浮游植物的临界流速

Tab. 1 Critical flow velocities for phytoplankton

\begin{tabular}{cccc}
\hline 国别/区域 & 研究方法 & 藻种类 & 临界流速 $/(\mathrm{m} / \mathrm{s})$ \\
\hline 澳大利亚/Barwon-Darling & 现场实验 & Anabaena circinalis & $0.05^{[7]}$ \\
& & & $0.03^{[6]}$ \\
三峡支流大宁河 & 现场实验 & Chl. a 代表的藻类参数 & $00^{[24]}$ \\
嘉陵江 & 现场实验 & Chl. a 代表的藻类参数 & $0.04^{[25]}$ \\
嘉陵江 & 室外模拟 & Chl. a 代表的藻类参数 & $0.08 \sim 0.14^{[26]}$ \\
三峡库区 & 室外模拟 & 多种藻类 & $0.05^{[27]}$ \\
重庆嘉陵江段 & 室内模拟 & 多藻种混合 & $0.05^{[28]}$ \\
\hline
\end{tabular}

然而, 由于不同的研究在时间尺度和空间尺度上存在局限性, 临界流速往往差异很大 (表 1). 关于水动 力对藻类生长的影响机制, 目前国内外已有一些研究. 然而, 已有研究成果未能很好地探明水动力对藻类生 长的影响机理, 尚不能较好地解释所观测到的现象. Bronnenmeier 等 ${ }^{[29]}$ 提出的紊动导致藻细胞壁破损死亡、 从而抑制藻类生长的机制, 较好地解释了高强度紊动对藻类生长的抑制作用, 但无法解释低强度紊动条件 下藻类生长受到促进的现象; Warnaars 等 ${ }^{[30]}$ 提出的紊动导致藻细胞外扩散层 (diffusive sublayer) 厚度变薄 (计算结果显示, 天然湖泊中, 较强紊动下扩散层厚度仅为静水时的 $1 / 10$ )、因而有利于周边水体向藻细胞输 送营养物质的机制, 较好地解释了低强度紊动对藻类生长的促进作用, 但无法解释紊动增强后藻类生长被 抑制的现象; 我们多年来对天然湖泊的观测及室内实验均发现,在远低于文献报道的导致细胞破损的水动 力条件下,仍可观测到藻类生长明显受抑制的现象 ${ }^{[14,31]}$, 用上述两种机制均无法解释.

\section{3 水动力对藻类影响的概念机制}

\section{1 水动力条件对藻类影响机制的讨论}

水动力除了对藻类产生直接影响之外, 还通过与生态系统之间的复合作用, 即改变藻类的生态位, 进而 对藻类产生影响. Hilt 等 ${ }^{[32]}$ 研究发现水动力对藻类生态位转换的作用, 比如将光照需求较低的优势藻种从 浑浊水域带进清流水域, 通过改变光照条件对藻类生长产生抑制作用. Moreno-Ostos 和 Blukacz 等 ${ }^{[33-34]}$ 对风 生流垂向扰动对浮游、下沉式藻类的影响进行分析. Okely 等 ${ }^{[35]}$ 提出了水力输送过程中上升流对藻类的影 响. 当把生态位改变与细胞传质、细胞力学综合分析时, 才能很好地解释水动力对藻类的影响机理. 孔繁翔 等 ${ }^{[36]}$ 认为, 通过垂直移动避免光抑制并不是蓝藻的主要策略, 一定的紊动和光照的耦合可能是太湖蓝藻优 势形成的驱动机制; Cozar 等 ${ }^{37]}$ 发现紊动及其引起的营养盐流动是造成藻类群落结构变化的关键因素. 这种 基于水体置换原理的稀释效应、机械输移效应、垂向混合效应主要通过改变藻类的生态位来影响藻类的 生长.

水动力条件在环境中也不能作为一个孤立条件进行研究, 应该综合考虑营养盐、光及温度等的协同作 用. 朱宜平等 ${ }^{[13]}$ 在崇明岛中心湖进行的现场围隔实验发现, 水动力条件产生的剪切力通过促进水绵的营养 生殖和破坏浮游植物的光生境对浮游植物的生长产生重要的影响. 不同营养盐浓度带来的传质梯度的差异 与不同流速带来的传质边界层厚度的差异协同作用, 通过传质速率才是最终控制细胞营养物质吸收的关 键, 进而影响藻细胞的生长. 颜润润等 ${ }^{[38]}$ 认为紊动对贫营养水平条件下微囊藻生长影响显著, 富营养水体中 紊动对微囊藻比增长率和最大生物量的影响均不明显. 吴晓辉等 ${ }^{[39]}$ 对国内外相关研究进行了归纳分析, 认 为紊动对藻类生长的影响机理主要是引起水下光强和营养盐输送的变化; Hondzo 等 $^{[40]}$ 指出紊动条件下藻 类的生长不仅依赖于对光的利用, 还与营养盐的扩散关系密切; Wang 等 ${ }^{[41]}$ 也提出了与 Hondzo 等相似的结 论, 在湍流环境下, 细胞对磷的吸收速率有所增加. Arin 等 ${ }^{[42]}$ 和 Iversen 等 ${ }^{\left[{ }^{[43}\right]}$ 则认为贫营养条件下紊动对藻 类生物量的影响很小, 而富营养条件下, 紊动加速离子向藻细胞表面移动, 从而刺激藻类对营养盐的吸收. 张毅敏等 ${ }^{[44]}$ 认为不同的营养状态, 临界流速是不同的. 在 $\mathrm{N}: \mathrm{P}$ 为 $4.5: 1$ 的情况下推测临界流速为 $0.50 \mathrm{~m} / \mathrm{s}$, 在 $\mathrm{N}: \mathrm{P}$ 为 $2.7: 1$ 的情况下推测临界流速为 $0.30 \mathrm{~m} / \mathrm{s}$. 不同温度下铜绿微囊藻生长临界流速的差异也可以归结 为传质问题. 王婷婷等 ${ }^{[45]}$ 比较了不同温度下水流对铜绿微囊藻生长的影响, 发现水体流动使微囊藻生长滞 
后, 改变其对数生长期持续时间和比增长率, 直接影响微囊藻的最大生物量, 且水温在 $25^{\circ} \mathrm{C}$ 时, 微囊藻细胞 生理活性增加, 对水流适应能力增强, 当流速达到 $0.15 \mathrm{~m} / \mathrm{s}$ 时获得最大生物量. 基于反应热力学, 升温有助 于加速生长, 同时加速传质也有利于加速生长, 两者的协同作用表现为不同温度下具有不同的临界流速. 以 上研究表明,水动力对藻类的影响表现为改变传质阻力.

随着流速的进一步增大, 在水体紊动对藻类的影响实验中发现, 水流剪切力会对细胞造成机械损伤 ${ }^{[31]}$, 细胞的剪切形变会对光系统 II 的活性造成影响, 甚至可能存在更大流速, 能造成细胞破碎.

\section{2 水动力对藻类影响的 3 种不同概念机制}

从 2007 年开始, 在崇明岛前卫村中心湖开展的一系列野外围隔实验中, 发现 $0.30 、 0.15 、 0.10 、 0.06$ 和 $0.03 \mathrm{~m} / \mathrm{s}$ 的流速条件均对浮游植物生物量产生了明显的抑制作用, 相对于静止的围隔, 浮游植物生物量分别 降低了 $37.5 \% 、 26.1 \% 、 36.7 \% 、 20.3 \%$ 和 $26.3 \%{ }^{[46]}$. 通过对围隔环境因子的分析,认为除了水下光强变化 的影响,还存在其他重要机制. 在围隔实验中,通常观 测到的都是水动力对铜绿微囊藻生长的抑制效应. 然 而在人工气候箱的烧杯实验中,通过准确的紊动控制 及不同紊动下的多组平行实验, 观测到了在温度适宜、 营养盐和光照充足条件下较完整的紊动对铜绿微囊藻 生长的效应, 且实验结果具有很好的再现性. 紊动对铜 绿微囊藻生长的效应可被分为 3 个区间 (图 1). 其中, 区间 $\mathrm{A}$ 内, 紊动促进生长; 区间 $\mathrm{B}$ 内, 紊动的促进效应 逐渐降低,但仍高于静水环境; 区间 $\mathrm{C}$ 内, 紊动抑制铜 绿微囊藻生长,其最大比增长率低于静水环境中的值.

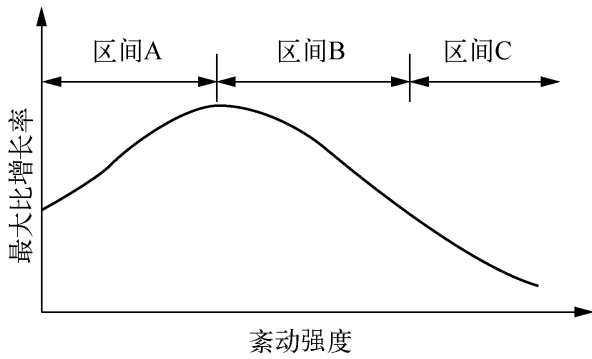

图 1 藻类最大比生长率-水动力强度关系

Fig. 1 Schema of relationship between maximum specific growth rate and hydrodynamic intensity

根据以上结论, 结合现有的研究进展, 我们认为国内外关于水动力影响藻类生长的机制解释存在混淆, 基于水体置换的影响机制主要体现在水动力对藻类的冲刷效应, 这也是常见的生态水力调度技术的依据, 这种技术在短期的置换周期内可以达到对藻类生长和水华控制的效果,但随着置换效应的消失, 原有生境 的恢复或藻类对新生境的适应,水华有可能再次暴发. 因此,当通过水体置换完成调水后,应保持水体中周 期性的流动效应, 即水动力对藻类小生境的影响. 归纳现有研究,水动力条件对藻类生长应存在 3 种概念机 制: (1) 小流速条件下,流态改变藻细胞外扩散层厚度,有利于水体向藻细胞输送营养物质,促进藻类生长; (2) 中等流速条件下, 紊动导致藻类营养盐吸收及光合作用能力受损, 抑制藻类生长; (3) 大流速条件下, 紊动所产生的水流剪切导致藻细胞壁破损死亡. 低强度紊动下,机制 1 起决定性作用, 促进藻类生长; 当紊 动增强到一定程度后, 机制 2 开始起决定性作用,藻类生长受到抑制; 高强度紊动下, 机制 2 和 3 共同发挥作 用, 藻类生长进一步受到抑制. 天然水体中紊动强度一般达不到藻细胞受机械损伤的程度 ${ }^{[47]}$, 藻类生长受抑 制应该是由于机制 2 在起决定性作用. 上述机制很好地解释了不同尺度条件下不同属细胞、同一属细胞的 水华藻类会有不同临界流速.

\section{3 面向管理需求的临界流速机制}

对于流量管理措施,笔者认为并不存在一个普遍的临界流速,在流量管理的应用中要针对不同的水体 对临界流速进行研究 ${ }^{[46]}$. 对于流量管理, 从工程实施的角度来看,现有的技术方案可分为四级尺度的管理 方案 ${ }^{[48]}$.

第一级、第二级流域尺度的管理以拦水蓄水调水方式为主. 针对三峡水库蓄水以来库区支流香溪河出 现的水华问题,我国学者发现利用上游水利水电工程调节上游来流量比及三峡水库小幅度水位波动 (10 $20 \mathrm{~cm} / \mathrm{d}$ ) 进行生态调度效果明显, 可望更好地抑制库湾水体富营养化和控制藻类生长 ${ }^{[49]}$. 许可等 ${ }^{[50]}$ 研究并 建立了基于日调节的三峡水库支流非汛期生态调度模型, 分析结果表明,增大水位波动和加快水体流速可 以显著改善水体水质,并能够缓解库区和支流的富营养化现状. 第三类流域采用以闸、坝为主的流量调度方 式,进行引水引潮排水调控, 以大多数中小型水库、一级流域支流为代表. 在澳大利亚, 较小的河面坡度和围 堰使得河流流速缓慢,致使 1991 年以来多次暴发水华事件,通过流速控制和流量管理,大大降低了水华暴 
发的风险. 如 Mitrovic 等 ${ }^{[7]}$ 对澳大利亚 Barwon-Darling 河及其支流的围堰池中卷曲鱼腥藻 (Anabaena circinalis) 研究发现, 当临界流速达到 $0.05 \mathrm{~m} / \mathrm{s}$ 时, 即可有效抑制这种藻类的生长和水华发生. 而 Mitrovic 等 $^{[6]}$ 对 Darling 河下游 Menindee 湖的研究发现, 流速为 $0.03 \mathrm{~m} / \mathrm{s}$ 足以防治该湖泊长时间的温度层结, 并能够有效抑 制蓝藻水华. 李锦秀等 ${ }^{[24]}$ 应用三峡库区支流大宁河 2003 年 9 月 17 日至 23 日的实测资料, 认为藻类在流速 接近 $0 \mathrm{~m} / \mathrm{s}$ 时, Chl. a 浓度达到最大值, 随着流速增大, Chl. a 浓度会逐渐变小. Long 等 ${ }^{[25]}$ 在研究水动力条件 对嘉陵江重庆主城段藻类生长的影响时, 认为最佳流速为 $0 \mathrm{~m} / \mathrm{s}$, 与现有研究不符, 提出临界流速的率定值 为 $0.04 \mathrm{~m} / \mathrm{s}$, 与刘信安等 ${ }^{[28]}$ 在对嘉陵江水进行的实验室模拟结果 $0.03 \mathrm{~m} / \mathrm{s}$ 基本吻合. 第四级流域为河网流 域;多采用闸门控制为主、水泵调控为辅的方式,一般包括中小型水库、灌溉、景观水体.

对临界流量进行归类分析, 可以作为水动力对藻类控制能力和控制手段的一个选择. 从水体置换和细 胞学两个方面, 可以将临界流速定义为以下两个方面:

基于水体置换的临界流速, 即间接临界流量控制, 其最终控藻手段是通过改变生态位实现. 对于河流湖 泊等流动性生态系统, 藻类的产生无法实现在固定水域的永久性停留, 流量管理的最初级阶段是实现对藻 类生境的更换作用. 通过上游清洁来水对本地产生的污染物质以及藻类浓度进行冲刷、迁徙, 降低该地区的 污染物质. 另外, 通过改变当地优势藻种的生境, 实现其在下游流域的生长抑制 ${ }^{[51]}$. 第一、二、三尺度水域调 控采用水坝闸门控制, 对流域水资源进行时间上的调配并兼顾饮用水、灌溉、航运、发电功能, 限于其功能应 用目标, 调节范围有限, 应该从基于水体置换的临界流速着手进行流量管理.

基于细胞学的临界流速, 即面向本地固有藻类生境, 基于流体对细胞营养物传质效率、光合作用效率以及细 胞结构完整性的研究. 第四级水域, 在闸门调配、辅助水洜调节, 以上海青草沙水库为例, 具有较短 $(15 \sim 28 \mathrm{~d})$ 的换水周期 ${ }^{[52]}$, 相比鄱阳湖年平均 $66 \mathrm{~d}$ 的换水周期及 $50: 1$ 的库容量, 具有更大的调节空间和可操控性, 可 从两个方面分别考虑流量管理策略,分别进行水华控制应急管理和水质维持流量管理.

\section{4 结论及展望}

以现有水动力对藻类影响机制的讨论为依据, 提出了水动力对藻类生长影响的 3 种不同的概念机制, 分别为: 低强度的水力扰动导致藻细胞外扩散层厚度变薄, 有利于周边水体向藻细胞输送营养物质, 促进藻 类生长; 中等强度的水力扰动导致藻类营养盐吸收及光合作用能力受损, 抑制藻类生长; 高强度的水流剪切 导致藻细胞壁破损. 在不同的水动力强度下这 3 种机制分别起决定性作用. 现有的流量管理中临界流速应 分别从水体置换和细胞学两方面考虑, 第一、二、三尺度水域由于功能受限, 应该从基于水体置换的临界流 速着手进行流量管理; 第四级水域具有更大的调节空间和可操控性, 可从两个方面分别考虑流量管理策略, 分别进行水华控制应急管理和水质维持流量管理.

由流量管理的局限性可以看出, 尽管国内外在水动力对浮游植物生长的影响机制方面取得了一定研究 成果, 但还没有彻底地揭示水动力对浮游植物生消的影响机理, 尤其是细胞学角度的水体紊动对藻类生长 的影响机制. 模拟实验和经验关系的建立仍是当前研究的主要手段, 与实际应用之间还有一定距离. 要全面 考虑水动力影响下浮游植物生消的环境调控机制, 并有效应用于流量管理, 仍需要大量长期的系列观测数 据作为支撑, 不管是室内模拟、室外模拟还是野外观测 , 目前观测数据的持续时间和观测参数的全面程度都 无法满足要求. 水动力对藻类生长的细胞学机制将是未来机理研究和实践应用的重点所在.

\section{5 参考文献}

[ 1 ] Reichwaldt ES, Ghadouani A. Effects of rainfall patterns on toxic cyanobacterial blooms in a changing climate: Between simplistic scenarios and complex dynamics. Water Research, 2012,46(5):1372-1393.

[ 2 ] Brookes JD, Carey CC. Resilience to blooms. Science, $2011,333(6052): 46-47$.

[ 3 ] Zhang HP, Zhu YP, Li FP et al. Nutrients in the wet deposition of Shanghai and ecological impacts. Physics and Chemistry of the Earth, 2011,36(9/10/11):407-410.

[4] 王成林,张 咏,张宁红等.太湖藻源性“湖泛”形成机制的气象因素分析. 环境科学,2011,32(2):401-408.

[5] 李 哲, 郭劲松,方 芳等. 三峡小江回水区蓝藻季节变化及其与主要环境因素的相互关系. 环境科学, 2010,31 (2) : 301-309. 
[ 6 ] Mitrovic SM, Hardwick L, Dorani F. Use of flow management to mitigate cyanobacterial blooms in the Lower Darling River, Australia. Journal of Plankton Research, 2011,33(2):229-241.

[ 7 ] Mitrovic SM, Oliver RL, Rees C et al. Critical flow velocities for the growth and dominance of Anabaena circinalis in some turbid freshwater rivers. Freshwater Biology, 2003 ,48(1):164-174.

[8] 梁培瑜,王 烜,马芳冰. 水动力条件对水体富营养化的影响. 湖泊科学, 2013,25(4):455-462.

[ 9 ] Istvánovics V, Honti M. Phytoplankton growth in three rivers: The role of meroplankton and the benthic retention hypothesis. Limnology and Oceanography, 2011 ,56(4) : 1439-1452.

[10] Desortová B, Puncochár P. Variability of phytoplankton biomass in a lowland river: Response to climate conditions. Limnologica, $2011,41(3): 160-166$.

[11] 王玲玲, 戴会超, 蔡庆华. 香溪河水动力因子与叶绿素 $\mathrm{a}$ 分布的数值预测及相关性研究. 应用基础与工程科学学 报,2009,17(5):652-658.

[12］李飞鹏. 封闭水体浮游植物生消的环境调控机制及水力调度研究 [学位论文].上海: 同济大学,2012.

[13] 朱宜平,张海平,李飞鹏等. 水动力对浮游生物影响的围隔研究. 环境科学, 2010,31(1):69-75.

[14] 李飞鹏,张海平,陈 玲. 小型封闭水体环境因子与叶绿素 $\mathrm{a}$ 的时空分布及相关性研究. 环境科学, 2013,34(10): 3854-3861.

[15] Paerl HW, Huisman J. Blooms like it hot. Science, 2008 ,320(5872) :57-58.

[16] 王丽平, 郑丙辉, 张佳否等. 三峡水库蓄水后对支流大宁河富营养化特征及水动力的影响. 湖泊科学, 2012,24(2): 232-237.

[17] 王红萍,夏 军,谢 平等. 汉江水华水文因素作用机理一基于藻类生长动力学的研究. 长江流域资源与环境, 2004,13 (3) :282-285

[18] 龙天渝, 蒙国湖, 吴 否等. 水动力条件对嘉陵江重庆主城段藻类生长影响的数值模拟. 环境科学, 2010,31(7): 1498-1503.

[19］龙天渝,周鹏瑞, 吴 否. 环境因子对香溪河春季藻类生长影响的模拟实验. 中国环境科学,2011,31(2):327-331.

[20] 王 华,逢 勇. 藻类生长的水动力学因素影响与数值仿真. 环境科学, 2008,29(4):884-889.

[21] 廖平安,胡秀琳. 流速对藻类生长影响的实验研究. 北京水利,2005,17(2):12-14.

[22］龙天渝,李祥华,吴 否. 灰色关联分析水位下降对藻类生长的影响. 三峡环境与生态, 2010,3 (3):8-10.

[23] 谢 敏. 针对河流水华现象的生态调度研究 [ 学位论文]. 南京:河海大学,2007.

[24] 李锦秀,杜 斌,孙以三. 水动力条件对富营养化影响规律探讨. 水利水电技术,2005,36(5):15-18.

[25] Long TY, Wu L, Meng GH et al. Numerical simulation for impacts of hydrodynamic conditions on algae growth in Chongqing Section of Jialing River, China. Ecological Modelling, 2011,222(1):112-119.

[26] 王利利. 水动力条件下藻类生长相关影响因素研究 [学位论文].重庆:重庆大学,2006.

[27］焦世珺. 三峡库区低流速河段流速对藻类生长的影响 [学位论文]. 成都:西南大学,2007.

[28] 刘信安,张密芳. 重庆主城区三峡水域优势藻类的演替及其增殖行为研究. 环境科学, 2008,29(7) : 1838-1843.

[29] Bronnenmeier R, Märkl H. Hydrodynamic stress capacity of microorganisms. Biotechnology and Bioengineering , 1982,24 (3) : $553-578$.

[30] Warnaars TA, Hondzo M, Carper MA. A desktop apparatus for studying interactions between microorganisms and smallscale fluid motion. Hydrobiologia, 2006,563(1):431-443.

[31］张月红. 水体紊动对铜绿微囊藻和四尾栅藻生长的影响 [学位论文].上海: 同济大学,2014.

[32] Hilt S, Gross EM, Hupfer M et al. Restoration of submerged vegetation in shallow eutrophic lakes - A guideline and state of the art in Germany. Limnologica, 2006,36(3):155-171.

[33] Moreno-Ostos E, Cruz-Pizarro L, Basanta A et al. The influence of wind-induced mixing on the vertical distribution of buoyant and sinking phytoplankton species. Aquatic Ecology, 2009,43(2):271-284.

[34] Blukacz E, Shuter B, Sprules W. Toward understanding the relationship between wind conditions and plankton patchiness. Limnology and Oceanography, 2009,54(5):1530.

[35] Okely P, Imberger J. Horizontal transport induced by upwelling in a canyon-shaped reservoir. Hydrobiologia, 2007,586 (1) $: 343-355$.

[36] 孔繁翔,宋立荣. 蓝藻水华形成过程及其环境特征研究. 北京:科学出版社,2011.

[37] Cozar A, Echevarria F. Size structure of the planktonic community in microcosms with different levels of turbulence. Scien- 
tia Marina, 2005,69(2) : 187-197.

[38] 颜润润,逢 勇. 不同风等级扰动对贫富营养下铜绿微囊藻生长的影响. 环境科学, 2008,29(10):2749-2753.

[39] 吴晓辉,李其军. 水动力条件对藻类影响的研究进展. 生态环境学报,2010,19(7):1732-1738.

[40 ] Hondzo M, Warnaars TA. Coupled effects of small-scale turbulence and phytoplankton biomass in a small stratified lake. Journal of Environmental Engineering-Asce, 2008 ,134 ( 12):954-960.

[41] Wang P, Shen H, Xie P. Can hydrodynamics change phosphorus strategies of diatoms? - Nutrient levels and diatom blooms in lotic and lentic ecosystems. Microbial Ecology, 2012,63(2) :369-382.

[42] Arin L, Marrase C, Maar M et al. Combined effects of nutrients and small-scale turbulence in a microcosm experiment. I. Dynamics and size distribution of osmotrophic plankton. Aquatic Microbial Ecology, 2002,29(1):51-61.

[43] Iversen KR, Primicerio R, Larsen A et al. Effects of small-scale turbulence on lower trophic levels under different nutrient conditions. Journal of Plankton Research, 2010,32(2):197-208.

[44] 张毅敏,张永春,张龙江等. 湖泊水动力对蓝藻生长的影响. 中国环境科学, 2007,27(5):707-711.

[45] 王婷婷,朱 伟,李 林. 不同温度下水流对铜绿微囊藻生长的影响模拟. 湖泊科学,2010,22(4):563-568.

[46] Li FP, Zhang HP, Zhu YP et al. Effect of flow velocity on phytoplankton biomass and composition in a freshwater lake. Science of the Total Environment, $2013, \mathbf{4 4 7}$ (1):64-71.

[47] 安 强,龙天渝,刘春静等. 雷诺数对藻类垂向分布特性的影响. 湖泊科学,2012,24(5):717-722.

[48］曾肇京,王俊英.关于流域等级划分的探讨. 水利规划,1996,(1) :1-5.

[49] 王玲玲, 戴会超, 蔡庆华. 香溪河生态调度方案的数值模拟. 华中科技大学学报: 自然科学版, 2009,37(4): 111-114.

[50] 许 可,周建中,顾 然等. 基于日调节过程的三峡水库生态调度研究. 人民长江,2010,41(10):56-58.

[51] Stal LJ, Moezelaar R. Fermentation in cyanobacterial. FEMS microbiology Reviews, 1997,21(2):179-211.

[52] 林卫青, 顾玉亮, 卢士强等. 防止藻类过度繁殖的青草沙水库合理水力停留时间初探. 给水排水, 2009,35 (9): 60-62. 